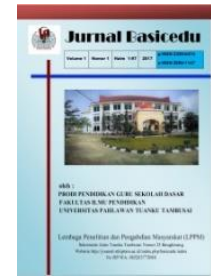

\title{
Pengaruh Kemandirian Belajar Terhadap Hasil Belajar Matematika Siswa di Sekolah Dasar
}

\author{
Heltaria Siagian ${ }^{1}$, Jontra Jusat Pangaribuan ${ }^{2}$, Patri Janson Silaban ${ }^{3}$ \\ Program Studi Pendidikan Guru Sekolah Dasar, Universitas Katolik Santo Thomas Medan ${ }^{1,3}$ \\ Program Studi Bahasa Inggris, Universitas Katolik Santo Thomas Medan ${ }^{2}$ \\ E-mail : heltarias@gmail.com ${ }^{1}$ jontra_pangaribuan@ymail.com ${ }^{2}$ patri_silaban280188@yahoo.co.id ${ }^{3}$
}

\begin{abstract}
Abstrak
Penelitian ini bertujuan untuk mengetahui pengaruh kemandirian belajar terhadap hasil belajar matematika siswa V di SD Negeri 112269 Padang Lais Tahun Pembelajaran 2020/2021. Populasi penelitian ini adalah seluruh siswa SD Negeri 112269 berjumlah 224 siswa. Sampel yang digunakan dalam peneltian ini adalah purposive sampling dalam hal ini peneliti memilih kelas $\mathrm{V}$ yang berjumlah 43 siswa untuk dijadikan sebagai sampel dalam penelitian ini. Pada penelitian ini peneliti menggunakan metode kuantitativ jenis survey metode yang digunakan dalam penelitian ini adalah metode kuantitatif untuk menguji hipotesis dengan menggunakan teknik hipotesis, teknik hipotesis yang digunakan adalah hipotesis uji t. Hasil penelitian ini menunjukkan bahwa kemandirian belajar memiliki rata-rata 84,90 dengan kategori rendah dan hasil belajar memiliki ratarata 69,06 dengan kategori rendah hal ini didukung dengan hasil pengujian hipotesis uji $t$ dimana $t_{\text {hitung }}>t_{\text {tabel }}$ yaitu 2,029>1,681 maka $\mathrm{H}_{0}$ diterima yaitu ada pengaruh kemandirian belajar yang signifikan antara kemandirian belajar terhadap hasil belajar matematika siswa kelas V di SD Negeri Padang Lais Tahun Pembelajaran 2020/2021.
\end{abstract}

Kata kunci: pengaruh, kemandirian belajar, hasil belajar

\section{Abstract}

This study aims to determine the effect of independent learning on student mathematics learning outcomes at SD Negeri 112269 Padang Lais for the 2020/2021 academic year. The population of this study were all students of SD Negeri 112269 totaling 224 students. The sample used in this research was purposive sampling, in this case the researcher chose class $V$, which amounted to 43 students to be the sample in this study. In this study, researchers used a quantitative method. This type of survey method used in this study is a quantitative method to test the hypothesis using the hypothesis technique, the hypothesis technique used is the hypothesis $t$ test. The results of this study indicate that independent learning has an average of 84.90 with a low category and learning outcomes have an average of 69.06 with a low category.This is supported by the results of testing the hypothesis $t$ test where $t_{\text {count }}>t_{\text {table }}$ is $2.029>1.681$ then $\mathrm{HO}$ is accepted. that is, there is a significant effect of independent learning between independent learning on mathematics learning outcomes of fifth grade students at SD Negeri Padang Lais for the 2020/2021 academic year.

Keywords: influence, learning independence, learning outcomes

Copyright (c) 2020 Heltaria Siagian, Jontra Jusat Pangaribuan Patri Janson Silaban

$\checkmark$ Corresponding author

Address : Medan

ISSN 2580-3735 (Media Cetak)

Email : heltarias@gmail.com

ISSN 2580-1147 (Media Online)

Phone : 081264559084

DOI: https://doi.org/10.31004/basicedu.v4i4.528 
1364 Pengaruh Kemandirian Belajar Terhadap Hasil Belajar Matematika Siswa Kelas di Sekolah Dasar Heltaria Siagian, Jontra Jusat Pangaribuan Patri Janson Silaban

DOI: https://doi.org/10.31004/basicedu.v4i4.528

\section{PENDAHULUAN}

Pendidikan adalah proses belajar manusia untuk menjadi yang lebih baik. Pendidikan berlangsung sepanjang hayat manusia. Pendidikan mempunyai peranan yang sangat penting bagi perkembangan setiap individu, terutama untuk pembangunan bangsa dan negara. Pendidikan merupakan salah satu bagian yang saat diperhatikan oleh pemerintah di Indonesia. Manusia yang memiliki kepribadian baik inilah yang akan mampu mengubah keadaan suatu bangsa menjadi lebih baik. Berdasarkan Undangundang Sistem Pendidikan Nasional Republik Indonesia No. 20 tahun 2003 Bab 1 Pasal 1 (ayat 1) bahwa pendidikan adalah usaha sadar dan terencana untuk mewujudkan suasana belajar dan proses pembelajaran agar siswa secara aktif mengembangkan potensi dirinya untuk memiliki kekuatan spiritual keagamaan, pengendalian diri, kepribadian, kecerdasan, akhlak mulia, serta keterampilan yang diperlukan dirinya, masyarakat, bangsa dan negara. Karakteristik dan semangat yang dimiliki setiap siswa berbeda-beda. Salah satu karakter yang dapat dibentuk dengan metode pembelejaran yang tepat adalah karakter madiri siswa. Kata mandiri memiliki arti yaitu tidak tergantung kepada orang lain, bebas, dan dapat melakukan sendiri. (Rita Ningsih, 2016) kemandirian belajar adalah kemampuan seseorang dalam mengatur semua aktivitas pribadi, kompetensi, dan kecakapan secara mandiri berbekal kemampuan dasar yang dimiliki individu, khususnya dalam proses pembelajaran.

Kemandirian belajar merupakan faktor dari keberhasilan belajar siswa, dan sangat penting sehingga harus menjadi perhatian pihak-pihak yang terkait dalam dunia pendidikan (Yamin, 2013). Belajar mandiri adalah belajar yang dilakukan oleh peserta didik secara bebas menentukan tujuan belajarnya, arah belajarnya, merencanakan proses belajarnya, strategi belajarnya, menggunakan sumber-sumber belajar yang dipilihnya, membuat keputusan akademik, dan melakukan kegiatan untuk tercapainya tujuan pembelajaran. Untuk melakukan kegiatan belajar aktif dan bertanggung jawab yang didorong oleh motivasi diri sendiri demi tercapainya hasil belajar yang optimal (Silaban, 2017). matematika merupakan suatu syarat untuk melanjutkan pendidikan kejenjang berikutnya. Karena dengan belajar matematika, siswa akan belajar bernalar secara kritis, kreatif, dan aktif. Siswa akan berhenti mengerjakan soal matematika jika sudah merasa tidak dapat mengerjakannya sendri. Kemandirian belajar diperlukan untuk mempelajari materi mata pelajaran matematika. Hasil belajar merupakan cerminan dari usaha belajar, semakin baik usaha belajarnya, maka semakin baik pula hasil yang diraih. Cara belajar siswa memang dapat dikemas dengan efisien, hal ini dikarenakan waktu yang digunakan mencukupi. Akan tetapi kenyataannya sebagian besar siswa belum mempunyai kesadaran untuk melakukan kemandirian belajar. Peneliti mendapat informasi dari Ibu Sarah sebagai guru kelas V diSD Negeri 112269 Padang Lais, bahwa sebagian besar siswa belum memiliki kepercayaan diri untuk melaksanakan kemandirian belajar dalam mengerjakan tugas. Masih banyak siswa yang menunggu bantuan dari guru, teman, dan orang sekitarnya. Kemandirian belajar siswa 
1365 Pengaruh Kemandirian Belajar Terhadap Hasil Belajar Matematika Siswa Kelas di Sekolah Dasar Heltaria Siagian, Jontra Jusat Pangaribuan Patri Janson Silaban

DOI: https://doi.org/10.31004/basicedu.v4i4.528

sangat kurang dalam mata pelajaran matematika. Pembelajaran matematika sering dipandang sebagai pelajaran yang sulit, banyak siswa yang kurang percaya diri untuk mengerjakan tugasnya sendiri tanpa bantuan siapapun. Padahal kemandirian belajar sangat diperlukan untuk mempelajari materi mata pelajaran matematika. Karena siswa yang tidak memiliki rasa percaya diri akan memperoleh nilai di bawah KKM (Ketuntasan Kriteria Minimum) pada pembelajaran matematika. Oleh karena itu, kepala sekolah dan guru bekerja sama untuk membantu siswa yang bermasalah agar hasil belajarnya lebih baik lagi.

Berdasarakan pernyataan di atas dapat dilihat dari nilai matematika siswa kelas $\mathrm{V}$ pada materi kecepatan dan debit di SD Negeri 112269 Padang Lais. Hasilnya menunjukkan bahwa nilai ulangan harian siswa sebagian besar masih dibawah KKM yaitu nilai 70. Untuk lebih jelas dapat dilihat pada tabel berikut.

Tabel 1. Nilai Ulangan Harian Matematika Siswa Kelas V Pada Materi Kecepatan dan Debit Di SD Negeri 112269 Padang LaisTahun Pembelajaran 2019/2020

\begin{tabular}{ccc}
\hline Nilai KKM & Jumlah Siswa & $\begin{array}{c}\text { Presentase } \\
(0 \%)\end{array}$ \\
\hline$>70$ & 19 & $44,19 \%$ \\
\hline$<70$ & 24 & $55,81 \%$ \\
\hline Jumlah & 43 & $100 \%$ \\
\hline
\end{tabular}

Sumber: data dari guru kelas V di SD Negeri 112269 Padang Lais

Berdasarkan tabel diatas dapat kita lihat nilai yang diperoleh siswa kelas V di SD Negeri 112269 Padang LaisTahun ajaran 2019/2020 yang menunjukkan bahwa dari 43 siswa, terdapat 24
$(55,81 \%)$ siswa yang tidak tuntas dan $19(44,19 \%)$ siswa yang tuntas mencapai KKM yang ditetapkan sekolah. Itu artinya untuk pelajaran matematika masih rendah. Dalam hal ini penting kesadaran pada diri siswa untuk melakukan kemandirian belajar sebagai salah satu faktor penting untuk mencapai tujuan pembelajaran, maka peneliti tertarik untuk melakukan penelitian mengenai Pengaruh Kemandirian Belajar Terhadap Hasil Belajar Matematika Siswa Kelas V di SD Negeri 112269 Padang Lais Tahun Pembelajaran 2019/2020. Berdasarkan uraian latar belakang dan identifikasi masalah di atas maka peneliti membatasi masalah-masalah yang ada. Batasan masalah yang akan dikaji adalah pengaruh kemandirian belajar terhadap hasil belajar matematika siswa kelas kelas $\mathrm{V}$ pada materi kecepatan dan debit diSD Negeri 112269 Padang Lais Tahun Pembelajaran 2019/2020.

Maka masalah yang akan diteliti dapat di rumuskan sebagai berikut:

1. Bagaimana keadaan kemandirian belajar siswa kelas V pada materi kecepatan dan debit di SD Negeri 112269 Padang Lais Tahun Pembelajaran 2019/2020?

2. Bagaimana hasil belajar siswa dalam pelajaran matematika kelas $\mathrm{V}$ siswa pada materi kecepatan dan debit di SD Negeri 112269 Padang Lais Tahun Pembelajaran 2019/2020?

3. Apakah ada pengaruh kemandirian belajar siswa terhadap hasil belajar matematika siswa kelas V di pada materi kecepatan dan debit di SD Negeri 112269 Padang Lais Tahun Pembelajaran 2019/2020? 
1366 Pengaruh Kemandirian Belajar Terhadap Hasil Belajar Matematika Siswa Kelas di Sekolah Dasar Heltaria Siagian, Jontra Jusat Pangaribuan Patri Janson Silaban

DOI: https://doi.org/10.31004/basicedu.v4i4.528

Tujuan yang ingin dicapai dalam penelitian ini adalah sebagai berikut:

1. Untuk mengetahui kemandirian belajar siswa kelas V pada materi kecepatan dan debit di SD Negeri 112269 Padang Lais Tahun Pembelajaran 2019/2020.

2. Untuk mengetahui hasil belajar siswa dalam pelajaran matematika kelas $\mathrm{V}$ pada materi kecepatan dan debit di SD Negeri 112269 Padang Lais Tahun Pembelajaran 2019/2020.

3. Untuk mengetahui apakah terdapat pengaruh kemandirian belajar siswa terhadap hasil belajar matematika siswa kelas $\mathrm{V}$ pada materi kecepatan dan debit di SD Negeri 112269 Padang Lais Tahun Pembelajaran 2019/2020.

\section{METODE}

Adapun metode penelitian yang digunakan dalam peneitian ini adalah metode kuantitatif survei. Sugiyono (2016: 24) metode penelitian survei adalah metode penelitian kuantitatif yang digunakan untuk mendapatkan data yang terjadi pada masa lampau atau saat ini, tentang keyakinan, pendapat, karakteristik, perilaku, hubungan variabel sosiologisndan psikologis dari sampel yang diambil dari populasi tertentu, teknik pengumpulan data dengan pengamatan (wawancara atau kuesioner) dan hasil penelitian cenderung untuk digeneralisasikan. Penelitian ini bersifat asosiatif yaitu penelitian yang bertujuan untuk mengetahui pengaruh antara dua variabel atau lebih. Dalam penelitian ini terdapat dua variabel yang dipengaruhi yaitu variabel kemandirian belajar sebagai variabel terikat dan variabel hasil belajar matematikasiswa sebagai variabel bebas, kelas V di SD Negeri 112269

Padang Lais Tahun Pembelajaran 2019/2020.

\section{HASIL DAN PEMBAHASAN}

Data penelitian diperoleh dari siswa kelas V SD Negeri 112269 Padang Lais, data penelitian terdiri dari satu variabel bebas yaitu kemandirian belajar (X) dan variabel terikat (Y). Data kemandirian belajar (X) diperoleh dari kuesioner, dengan model berskala Likert dengan 4 (empat) opsi jawaban. Kuisioner tersebut dibagikan kepada 43 siswa. Data yang diperoleh dari kuesioner tersebut kemudian dilakukan tabulasi data untuk menggunakan rata-rata nilai rapor semester ganjil tahun pembelajaran 2019/2020.

Sebelum mengambil data pada sampel peneliti terlebih dahulu dilakukan pengambilan data untuk diuji validitas dan realibilitas kuisioner. Jumlah instrumen kuisioner kemandirian belajar sebanyak 50 butir pernyataan, dan sebanyak 33 butir pernyataan yang dinyatakan valid serta reliabel. Setelah dilakukan uji validitas dan realibilitas selanjutnya kuisioner tersebut digunakan untuk mengambil ata pada sampel dan hasilnya disajikan dalam bentuk tabulasi data agar bisa digunakan di dalam uji analisis dan uji hipotesis. Adapun distribusi frekuensi data tentang variabel kemandirian belajar dapat dilihat tabel dibawah ini.

Tabel 2. Frekuensi Siswa Kategori Kemandirian Belajar

\begin{tabular}{lcll}
\hline Skor & Frekuensi & Persentase & Kategori \\
\hline $94,65-100,8$ & 5 & $11,6 \%$ & $\begin{array}{l}\text { Sangat } \\
\text { Tinggi }\end{array}$ \\
\hline $90,55-94,65$ & 8 & $18,6 \%$ & Tinggi \\
\hline
\end{tabular}


1367 Pengaruh Kemandirian Belajar Terhadap Hasil Belajar Matematika Siswa Kelas di Sekolah Dasar Heltaria Siagian, Jontra Jusat Pangaribuan Patri Janson Silaban

DOI: https://doi.org/10.31004/basicedu.v4i4.528

\begin{tabular}{lcll}
\hline $86,45-90,55$ & 6 & $13,9 \%$ & Cukup \\
\hline $82,35-86,45$ & 4 & $9,3 \%$ & Kurang \\
\hline $76,2-82,35$ & 20 & $46,5 \%$ & Rendah \\
\hline
\end{tabular}

Berdasarkan tabel frekuensi kategori kemandirian belajar bahwa kategori kemandirian belajar sangat tinggi sebesar $11,6 \%$, kemudian kategori kemandirian belajar tinggi sebesar 18,6\%, untuk $13,9 \%$ termasuk kategori kemandirian belajar cukup, selanjutnya kategori kemandirian belajar kurang sebesar 9,3\%, serta yang mempunyai presentase tertinggi pada frekuensi kategori kemandirian belajar rendah sebesar 46,5\%. Sehingga dapat disimpulkan bahwa kemandirian belajar di SD Negeri 112269 Padang Lais rendah.

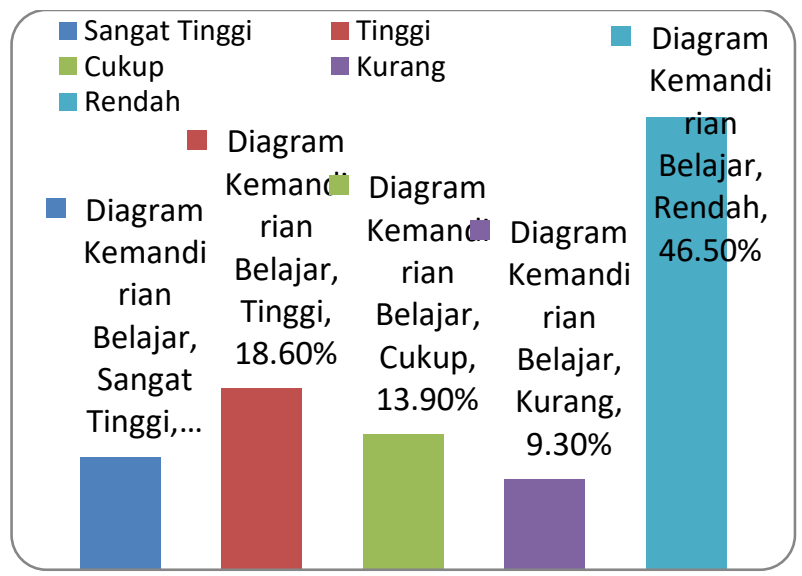

Gambar 1 Diagram Kemandirian Belajar

Berdasarkan diagram kemandirian di atas dapat disimpulkan bahwa kemandirian belajar di SD Negeri 112269 Padang Lais dalam kategori sangat tinggi sebesar 58,13\%.

Adapun distribusi frekuensi data tentang variabel hasil belajar siswa dapat dilihat pada tabel berikut.

\begin{tabular}{llccll}
\hline No & Skor & Frek & $\%$ & Kategori & $\begin{array}{l}\text { Klasifi } \\
\text { kasi }\end{array}$ \\
\hline 1 & $\begin{array}{l}83,75 \\
-95\end{array}$ & 8 & $\begin{array}{c}18,6 \\
\%\end{array}$ & Tuntas & $\begin{array}{l}\text { Sangat } \\
\text { Tinggi }\end{array}$ \\
\hline 2 & 76,25 & 5 & $\begin{array}{c}11,6 \\
\%\end{array}$ & Tuntas & Tinggi \\
& - & & & \\
& 83,75 & & & & \\
\hline 3 & 68,75 & 6 & 13,9 & Tidak & Cukup \\
& - & & $\%$ & Tuntas & \\
& 76,25 & & & & \\
\hline 4 & 61,25 & 8 & 18,6 & Tidak & Kurang \\
& - & & $\%$ & Tuntas & \\
& 68,75 & & & & \\
\hline 5 & $50-$ & 16 & 37,2 & Tidak & Rendah \\
& 61,25 & & $\%$ & Tuntas & \\
\hline & & & & & \\
\end{tabular}

Berdasarkan tabel frekuensi kategori hasil belajar di atas behwa siswa yang tuntas hanya 13 orang yaitu $30,2 \%$. Sedangkan siswa yang memiliki hasil belajar tidak tuntas ada 30 orang yaitu $69,7 \%$. Sehingga dapat disimpulkan baha hasil belajar siswa di SD Negeri 112269 Padang Lais dalam kategori tidak tuntas (rendah). Artinya hasil belajar siswa pada mata pelajaran matematika banyak yang belum tuntas (di bawah KKM). Untuk lebih jelasnya dapat dilihat pada diagram di bawah ini.

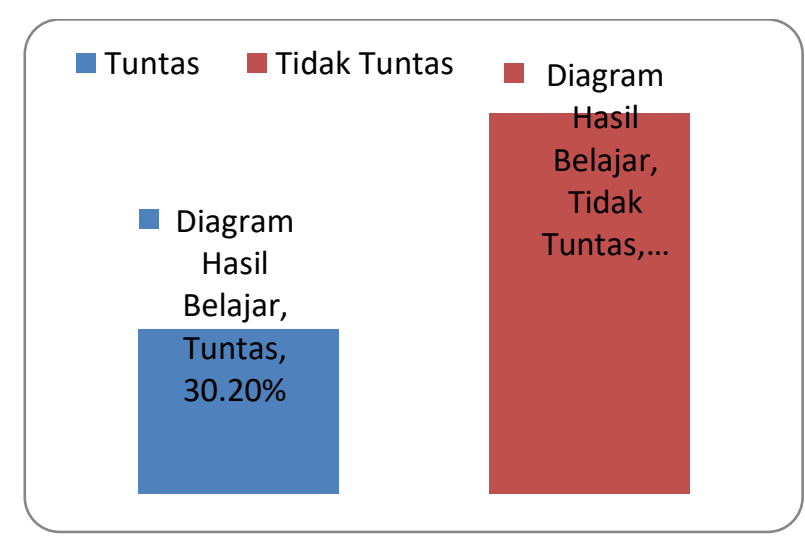

Gambar 2 Diagram Hasil Belajar

Berdasarkan diagram hasil belajar siswa di atas dapat disimpulkan bahwa hasil belajar siswa

Tabel 3 Frekuensi Kategori Hasil Belajar 
1368 Pengaruh Kemandirian Belajar Terhadap Hasil Belajar Matematika Siswa Kelas di Sekolah Dasar Heltaria Siagian, Jontra Jusat Pangaribuan Patri Janson Silaban

DOI: https://doi.org/10.31004/basicedu.v4i4.528

di SD Negeri 112269 Padang Lais dalam kategori tidak tuntas rendah yaitu $69,7 \%$.

\section{SIMPULAN}

Berdasarkan analsis data dan pengujian hipotesis serta pembahasan, maka dapat ditarik kesimpulan sebagai berikut:

1. Kemandirian belajar memiliki rata-rata sebesar 84,90 dapat disimpulkan bahwa kemandirian belajar di SD Negeri 112269 Padang Lais rendah. Bentuk kemandirian belajar yang dapat diterapkan pada diri siswa yaitu mampu belajar sendiri tanpa adanya dorongan dari orang lain. Namun, siswa masih banyak belajar jika adanya dorongan atau bantuan dari orang lain sehingga kemandirian belajar memperoleh kategori rendah.

2. Hasil belajar matematika siswa kelas V SD Negeri 112269 Padang Lais sebanyak 43 siswa sengan nilai rata-rata 69,06 dengan kategori rendah. Artinya bahwa anak yang memiliki kemandirian belajar yang rendah akan memperoleh hasil belajar yang rendah.

3. Terdapat pengaruh yang signifikan antara kemandirian belajar terhadap hasil belajar siswa kelas V di SD Negeri 112269 Padang Lais tahun pembelajaran 2019/2020. Hasil ini dibuktikan dengan memperoleh $t_{\text {hitung }}>t_{\text {tabel }}$ yaitu 2,029>1,681 dan signifikannya 0,049> 0,05 yang berarti $\mathrm{H}_{0}$ diterima yaitu bahwa kemandirian belajar memang berpengaruh terhadap hasil belajar.
Belajar Terhadap Hasil Belajar Matematika Siswa Kelas V SDN Gugus Sultan Agung Kecamatan Taman Kabupaten Pemalang. Universitas Negeri Malang.

Angraeni, R. D. (2016). Pengaruh Kemandirian Belajar Terhadap Hasil Belajar Matematika Kelas V SDN Puntadewa Kota Semarang. Universitas Negeri Semarang.

Lestari, D. I. (2019). Pengaruh Kemandirian Belajar Terhadap Hasil Belajar Matematika Siswa Kelas V SD SE-Dabin I Kota Tegal. Universitas Negeri Semarang.

Nurhayti, S. (2013). Pengaruh Kemandirian Belajar Anak Terhadap Hasil Belajar Matematika Siswa Kelas V SD. Jurnal Education, 1, 2. http://jurnal.fkip.uns.ac.id

Nurhidayah, S. (2019). Pengaruh Kemandrian Belajar Terhadap Hasil Belajar Bahasa Indonesia Kelas V SD Negeri Sekbin III Kabupaten Brebes. Universita Negeri Semarang.

Rita Ningsih, dkk. (2016). pengaruh kemandirian belajar dan perhatian orang tua terhadap prastasi belajar matematika. Jurnal Formatif, 6 , http:dx.doi.org/10.30998/formatif.v6il.754

Silaban, P. J. (2017). meningkatkan motivasi dan kemampuan matetamis siswa melalui alat peraga mentosori pada pelajaran matematika kelas IV SD ASISI Medan. Jurnal Elementary School, 7(4). http://doi.org/10.24114/esjp_gsd.v7i4.1018

Triadmajah, S. (2019). Pengaruh Kemandirian Belajar Terhadap Hasil Belajar IPA Siswa Kelas IV SD Negeri Gugus Hasanudin Kecamatan Bayu Putih Kabupaten Batang. Universitas Semarang.

Yamin, M. (2013). strategi dan metode dalam model pembelajaran. Gp Press Group.

\section{DAFTAR PUSTAKA}

Aliyah, L. F. (2019). Pengaruh Kemandiria 